\title{
A Brief History of the Institute of Physical Chemistry at the University of Zurich Written on the Occasion of the 75th Anniversary of the Institute 1931-2006§
}

\section{J. Robert Huber*}

\begin{abstract}
A brief history of the Institute of Physical Chemistry, University of Zurich, is presented ranging from the early days when Paul Karrer recognized and encouraged research into physical chemical processes, the creation of an Institute of Physical Chemistry in 1931 by Hans von Halban, and continuing through to the present. The professors and their research interests that have contributed to the excellent reputation of the Institute are described.
\end{abstract}

Keywords: Institute of Physical Chemistry · UZH

\section{Introduction}

Seventy-five years is a long time on the time scale of fast moving modern science. Fig. 1 illustrates this fact with the progress in optical spectroscopy over about this period.

The emission spectrum of benzene vapor on the left of Fig. 1 was taken around 1920 at our laboratory. The one on the right was recorded in the 90s also in our Institute and shows a high-resolution spectrum of nitric oxide NO. More specifically it represents the rotational spectrum of a selected vibrational level of this molecule which had just been created from a molecular photodissociation process. The wealth of molecular in-

${ }^{\star}$ Correspondence: Prof. em. J. R. Huber Institute of Physical Chemistry

University of Zurich

Winterthurerstrasse 190

$\mathrm{CH}-8057$ Zürich

Tel.: +41446354461

E-mail: jrhuber@pci.uzh.ch

$\S$ Text and figures were taken from a talk given on the occasion of the 75 years celebration on December

5th, 2006

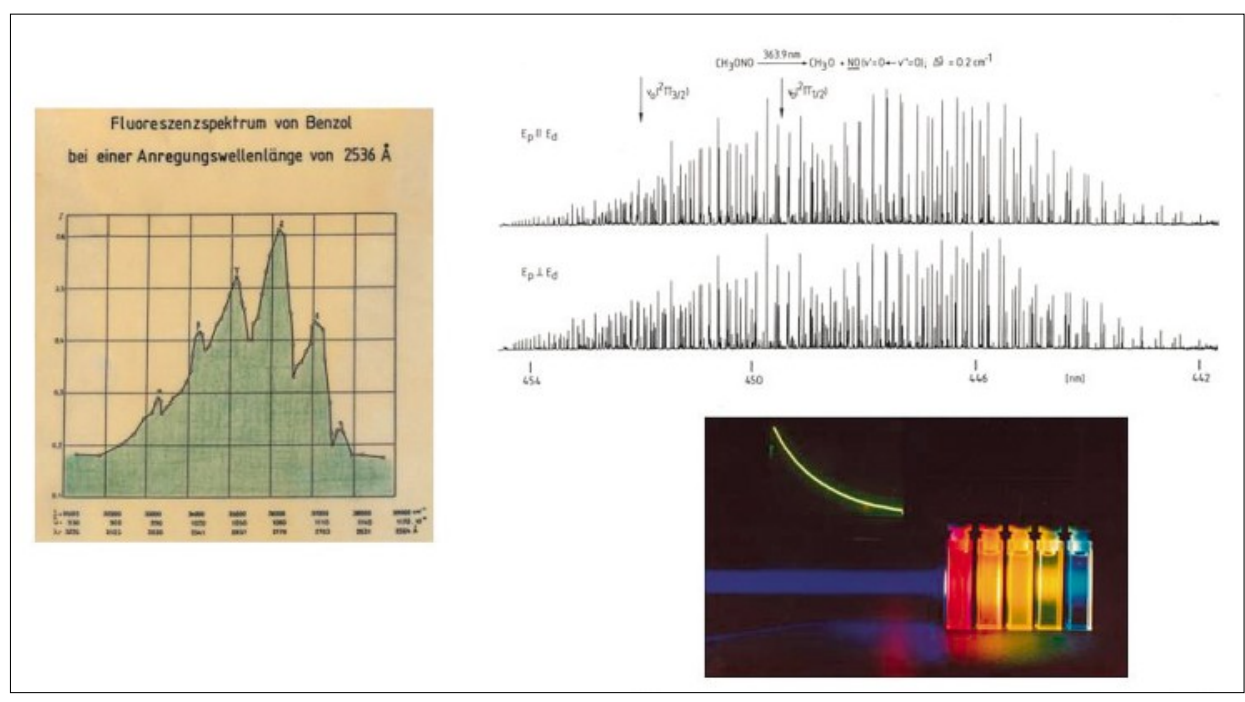

Fig. 1. Examples of optical spectroscopy over the past 75 years

formation we can acquire today from these high-resolution spectra is simply astonishing. But let us be humble; this progress was only possible by standing on the shoulders of great predecessors, to paraphrase Isaac Newton. In the following account we shall keep this in mind and thus will particularly emphasize the achievements of our predecessors at the Institute.

\section{$1909-1920$}

Let us start our brief history in 1909, when the Chemistry Institute of the University moved into a new building (Fig. 2).
This impressive building, located at Rämistrasse 74/76 across the street from the main building still exists, but is entirely changed inside by a breathtaking construction of a library designed by Santiago Calatrava.

1909 was also the year that Albert Einstein joined the University as Professor of Theoretical Physics. It was his first academic position as a professor.

In 1909 Alfred Werner was the Head of Chemistry, which at that time included all the disciplines of this field known today. Werner was a truly outstanding scientist and the founder of coordination chemistry, for which he was honored by the Nobel Prize in 1913. What may be less known is his keen 


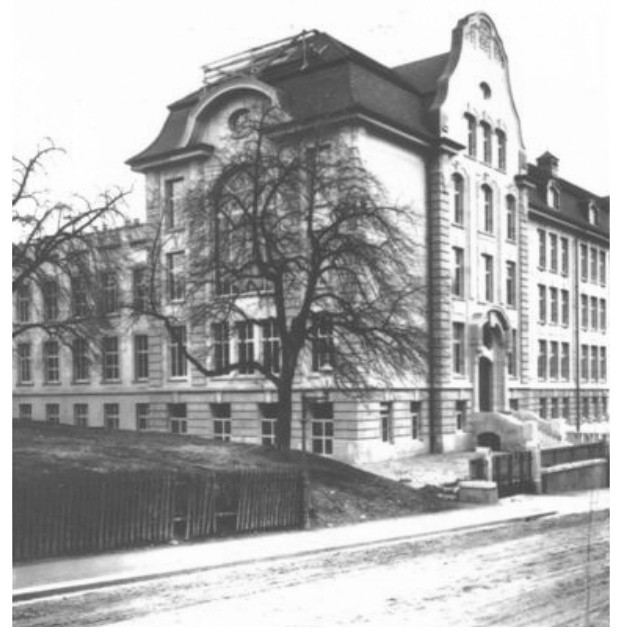

Fig. 2. 1909: The new Chemistry Building of the University in Rämistrasse 74/76

interest in, and his important contributions to optical spectroscopy in chemistry in collaboration with Paul Pfeiffer.

How progressive our University already was at that time may be illustrated in Fig 3. Since 1840, women were allowed to study at the University of Zurich. Even more astonishing might be the fact that in 1887 over 120 years ago - Rachel Lloyd finished her $\mathrm{PhD}$ work in chemistry with a thesis written in English. Werner's group always included a number of women in the $\mathrm{PhD}$ program. On Werner's right one recognizes his student Paul Karrer.

After a serious illness Werner retired in 1918. The Erziehungsdirektion (the cantonal body responsible for the University) appointed Paul Karrer (Fig. 4) as new Director of the Chemistry Institute. This turned out to be an excellent choice. Karrer's outstanding work on isolation, structure determination, and synthesis of natural products won him the Nobel Prize in 1937.

\section{0-1930}

This great organic chemist also realized in 1920 that physical chemistry is a field of

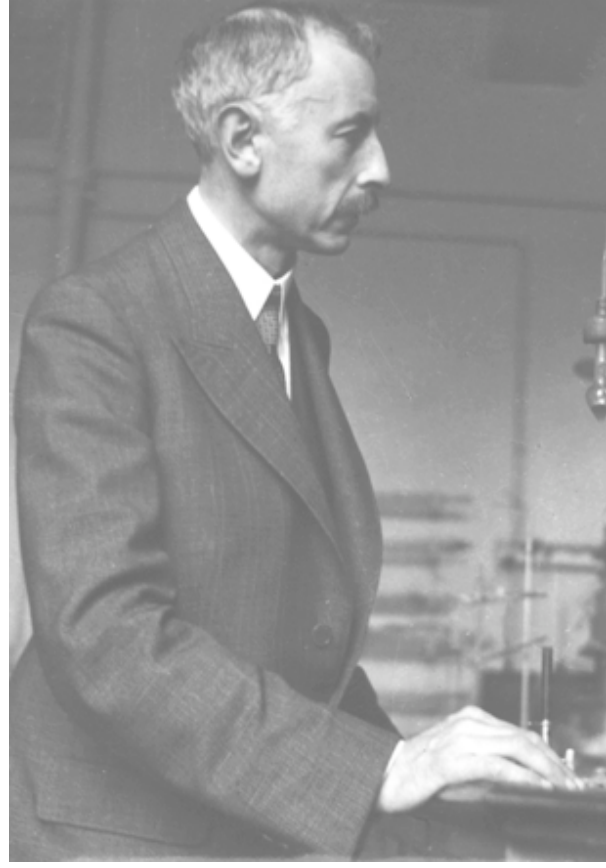

Fig. 4. Paul Karrer (Director 1918-1959)

its own. He established with caution - not a new Institute - but a new Department of Physical Chemistry, so he still could control chemistry at the University. What so ever, this was an excellent decision and the beginning of a successful story of physical chemistry at the University of Zürich.

After an extensive selection procedure, Victor Henri (Fig. 5), a well-known French scientist in the fields of molecular spectroscopy and photochemistry, was finally chosen as the first Professor of Physical Chemistry at the University.

Originally Henri was not a physical chemist. In 1900, when he was a young student, psychology and physiology were highly popular studies at universities. $\mathrm{He}$ studied these fields in Paris and Göttingen, completing his dissertation in physiology in Göttingen in 1897. Between 1907 and 1914 he worked as a lecturer at the Sorbonne in Paris. The quantitative investigations of physiological processes brought him to

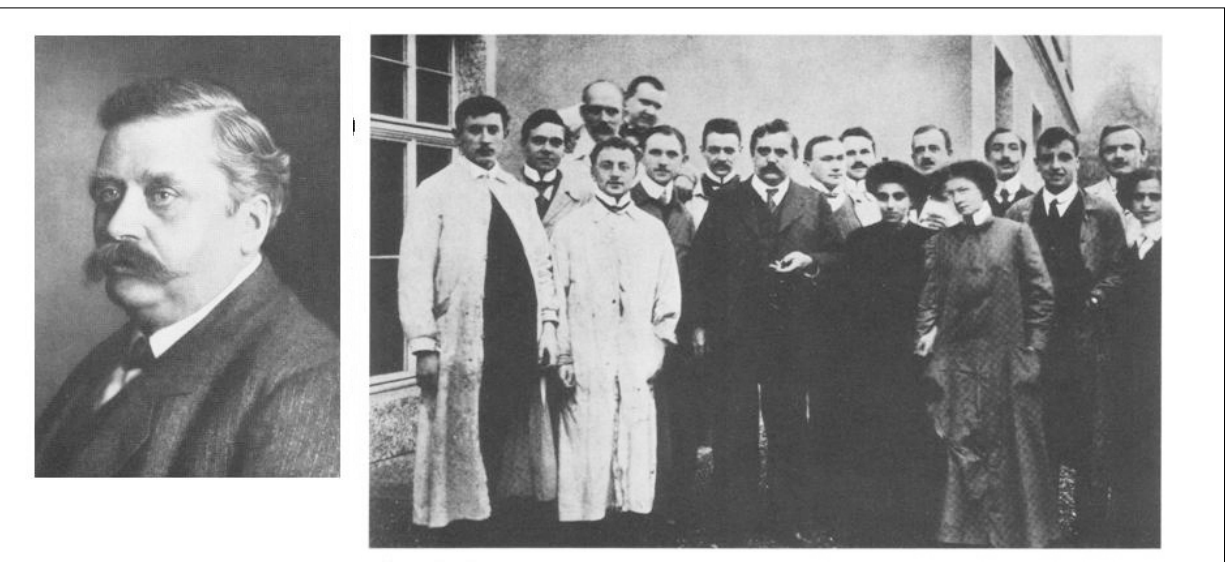

Fig. 3. Alfred Werner (Director 1893-1918/19) and his research group including several women

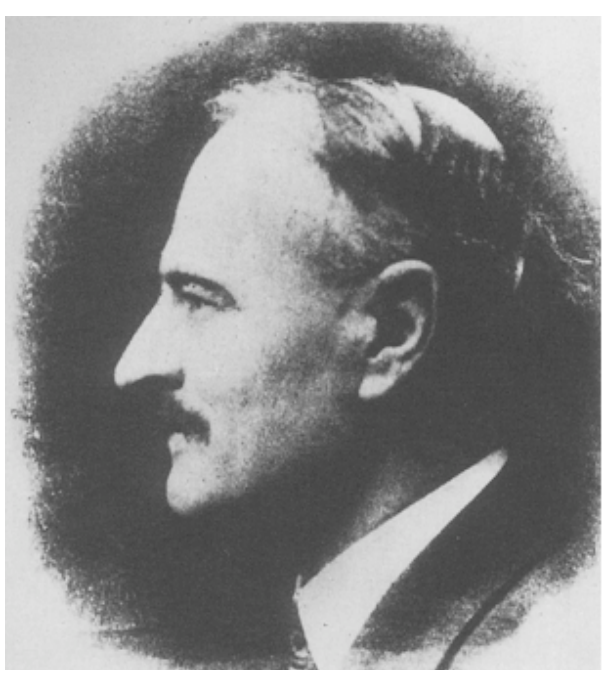

Fig. 5. Victor Henri (Director 1920-1930)

physical chemistry and later to physics. But let us illustrate this career with a few highlights of his research.

In 1905 Henri was still strongly involved in quantitative physiology, today we would say life science processes. On the basis of extensive experimental work, he formulated the general law of enzyme-catalyzed reactions (Eqn. (1)). His formula was consistent with all the data available. $\mathrm{K}$ denotes a constant and $m$ an enzyme-specific constant, $v_{0}$ stands for the rate of substrate consumption or product formation. Today the inverse of $\mathrm{m}$ is known as the Michaelis constant.

$$
v_{0}=-\frac{d[S]}{d t}=\frac{K_{2}[S]}{1+m[S]}
$$

Guided by Henri's result Michaelis and Menton contributed later a mechanistic picture to enzyme catalysis which today carries their names.

Before and during his stay at the University of Zürich (1920-1930), Henri's photochemical work was inspired by a paper of Albert Einstein. In 1912 Einstein had shown, basically by a thermodynamic approach, that in the photochemical reaction step given at the bottom of Fig. 6, n equals one for an energetically well-defined photon. Thus, you need one photon of a given energy to initiate the chemical reaction.

Together with René Wurmser, Henri verified experimentally Einstein's prediction and hence confirmed that $\mathrm{n}=1$. In addition however, they found two new and farreaching phenomena: The case of $n$ greater than one (you need more than one photon for a single reaction step) was attributed to 'Radiationless Transitions' in a molecule, i.e. a part of the absorbed photon-energy is transformed into heat. They also found the case for $\mathrm{n}$ smaller than one, indicating that one photon triggers more than one reaction. With this finding, they discovered the 


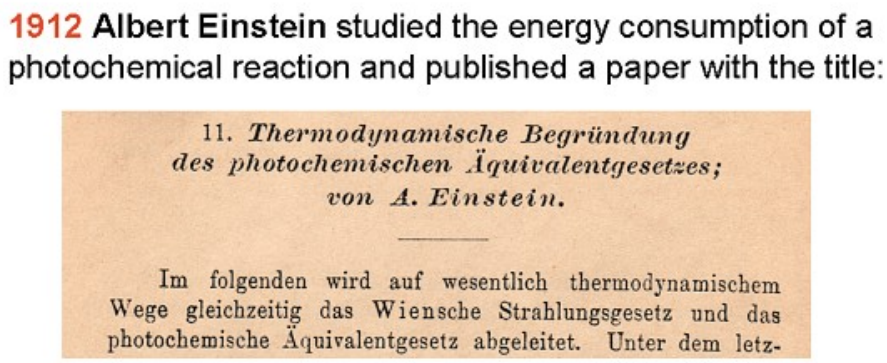

1912 Albert Einstein studied the energy consumption of a photochemical reaction and published a paper with the title:

11. Thermodynamische Begründung

des photochemischen ت̈quivalentgesetzes; von A. Einstein.

Im folgenden wird auf wesentlich thermodynamischem Wege gleichzeitig das Wiensche Strahlungsgesetz und das photochemische Äquivalentgesetz abgeleitet. Unter dem letz-

\section{$\mathrm{AB}+\mathrm{n} \cdot \mathrm{h} v \rightarrow \mathrm{AB}^{*} \rightarrow$ Products}

Fig. 6. 1912: Albert Einstein's paper on the energetics of photochemical reactions

'Chain Reaction' in photochemistry independently of Bodenstein.

Although Henri could not distinguish between intra- and inter-molecular radiationless processes, he proposed an intra-molecular process based on his extensive studies on the wavelength- and solvent-dependence of photochemical quantum yields.

The understanding of dynamical processes in molecules was one of Henri's main concerns. Combining photochemistry, more specifically photodissociation, with spectroscopy, Henri and Teves discovered in 1924 a new kind of dissociation process in polyatomic molecules which they termed 'Predissociation'. Observed in the formaldehyde spectrum - the original one is shown in Fig. 7 - this process is manifested by the loss of rotational structure accompanied by broadening of discrete vibra-

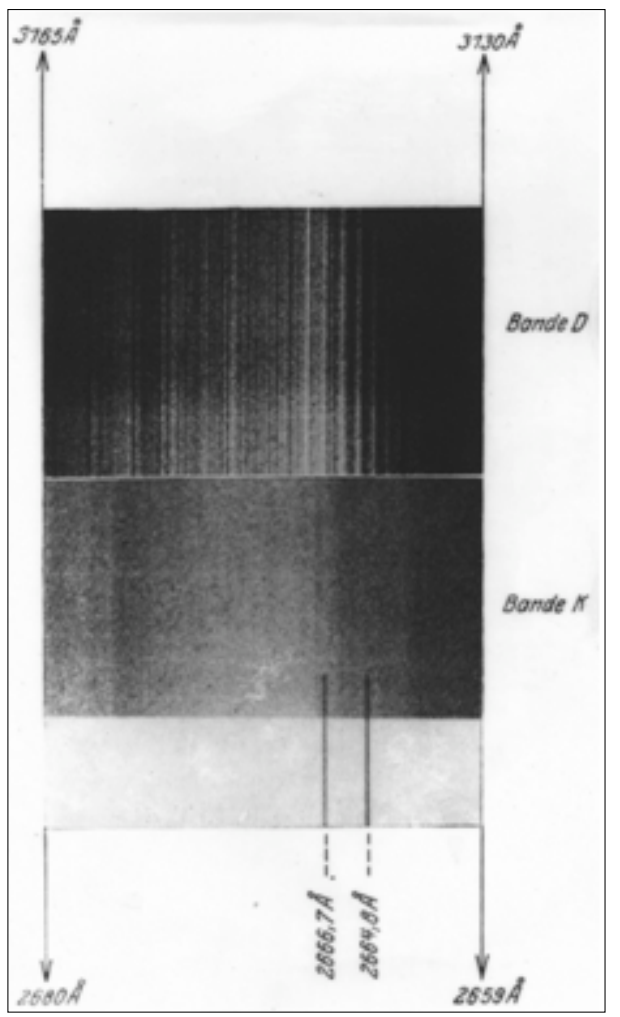

Fig. 7. 1924: Original formaldehyde spectrum tional levels of an excited electronic state of a molecule and was correctly explained by Henri as an interaction between a discrete state and a continuum state.

Looking for a theoretical interpretation, Henri found an expert theoretician in Gregor Wentzel who had just succeeded Erwin Schrödinger in our physics department. Wentzel treated this broadening of discrete states using quantum mechanics (Fig. 8) and obtained an expression very similar to the one he had found earlier for the explanation of the Auger effect. Today surprisingly this expression is known not as Wentzel's 'Golden Rule' but as Fermi's 'Golden Rule No. 2'!

It is interesting to add that in 1968 the intra-molecular radiationless transitions, observed by Wurmser and Henri almost fifty years before, were theoretically treated on the basis of the Golden Rule (Mordechai Bixon and Joshua Jortner).

Henri was also a pioneer in molecular spectroscopy. He wrote two volumes about the structure and spectroscopy of molecules, highly prized by Gerhard Herzberg, who later wrote his own books on this subject and thus created an invaluable document of spectroscopy.

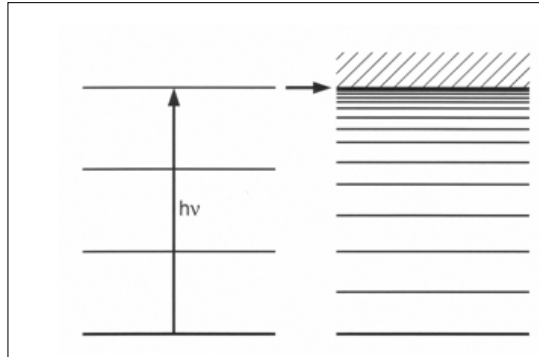

\section{Discrete States Continuum State}

Fig. 8. 1929: Scheme of Wenzel's treatment for the broadening of discrete states

Considering the poor spectroscopic tools at that time Henri and his students measured and analyzed spectra of molecules in a great way. Here we show the fluorescence spectrum and the absorption spectrum of benzene taken in 1922 (Fig. 9).

In 1930 Henri left the University for an industrial position in France. The Faculty suggested as his successor - quite surprisingly - not Werner Kuhn (a pupil of Henri), but Hans Ritter von Halban (Fig. 10), an inorganic chemist and former student of Alfred Werner. He had completed his habilitation at the University of Würzburg where he had become Professor in 1919.

Von Halban's research interest in Zürich centered on analytical chemistry using optical spectroscopy. In addition, he studied with great success the properties of electrolytes as well as solvent effects on chemical reactions.

\section{$1931-1963$}

In 1931 von Halban established an independent Institute of Physical Chemistry. This bold act gave us the opportunity to cel-

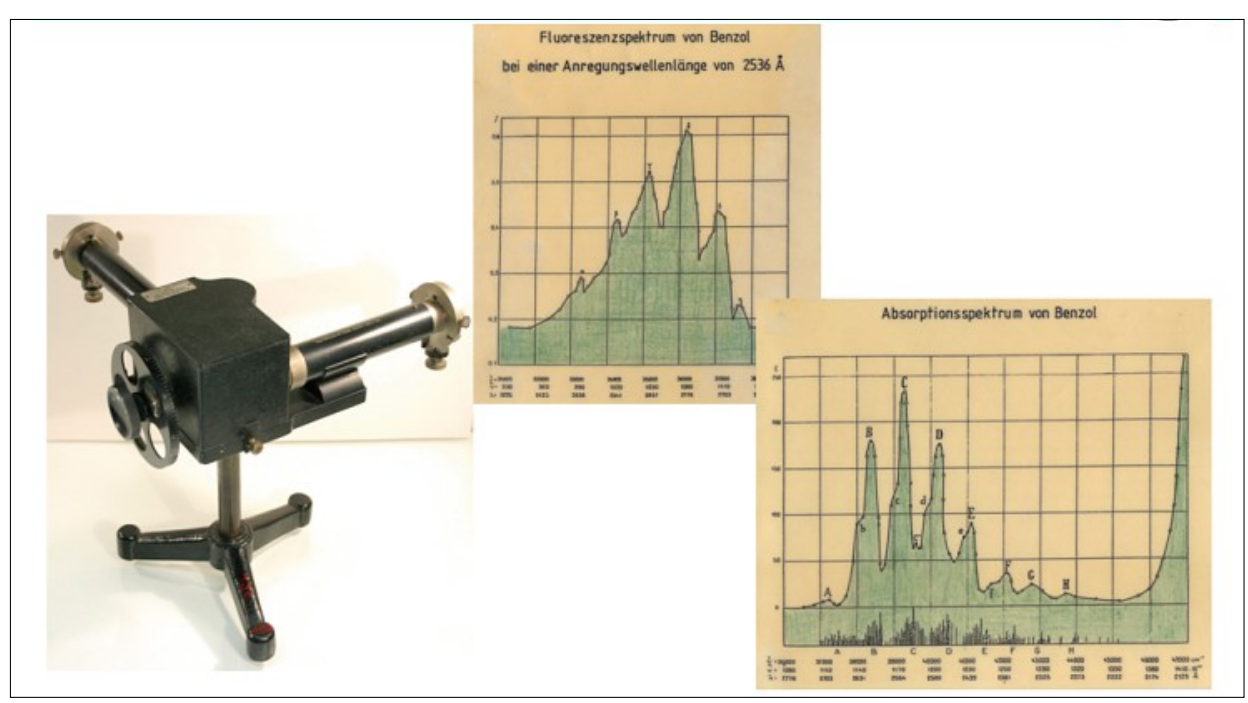

Fig. 9. 1922: The fluorescence and absorption spectra of benzene 


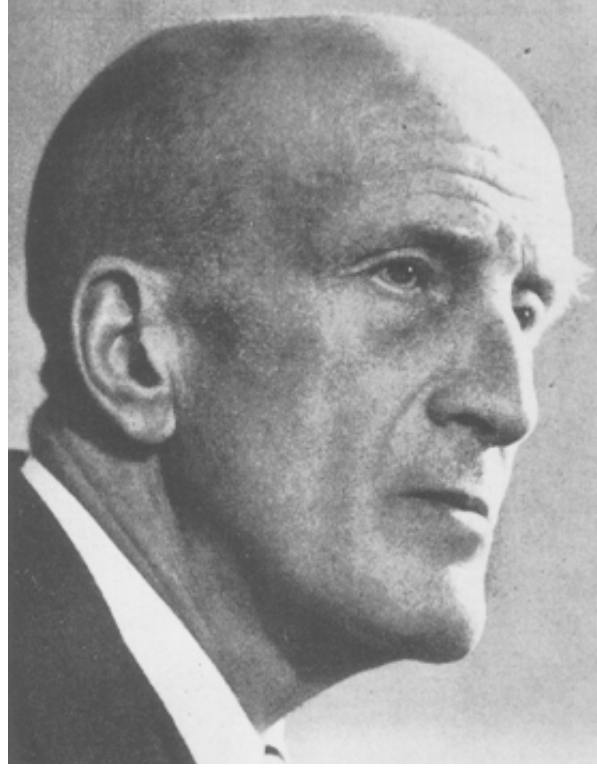

Fig. 10. Hans von Halban (Director 1930-1947)

ebrate our 75th birthday in 2006. That the director and the most influential person of chemistry, Paul Karrer, accepted this separation and that the Erziehungsdirektion and the government supported and realized it, was to a great extent the merit of Victor Henri, whose scientific oeuvre had gained high international recognition.

Von Halban's contribution to analytical chemistry was in the field of spectrophotometric microanalysis. In particular, precision measurement of low substance concentrations by new photometric techniques was one of his impressive achievements. His strength was, in contrast to Henri, not so much in finding new effects than in developing measurement techniques of existing methods to higher precision. An interesting project was concerned with the detection of fast reactions. Using a novel flow pipe apparatus he and his students achieved a time resolution of $1 \mathrm{~ms}$ in 1935. Today, applying laser technology and fast electronics the time resolution has improved by over 12 orders of magnitude, another example illustrating the progress over the last 75 years.

The successor of von Halban in 1947 was Klaus Clusius (Fig. 11), a well-established scientist with an excellent international reputation. He had completed his dissertation in 1928 at the Technical University Breslau, followed by research fellowships in Oxford (1929) and Leiden (1930). He made his habilitation at the University of Göttingen in 1931 and became Professor at the University of Würzburg in 1934 followed by a professorship at the University of Munich in 1936. His research fields were thermodynamics and kinetics. He had a thorough knowledge of modern physics. With his enthusiasm and his scientific drive he strongly changed and modernized the approach to science at our Institute.

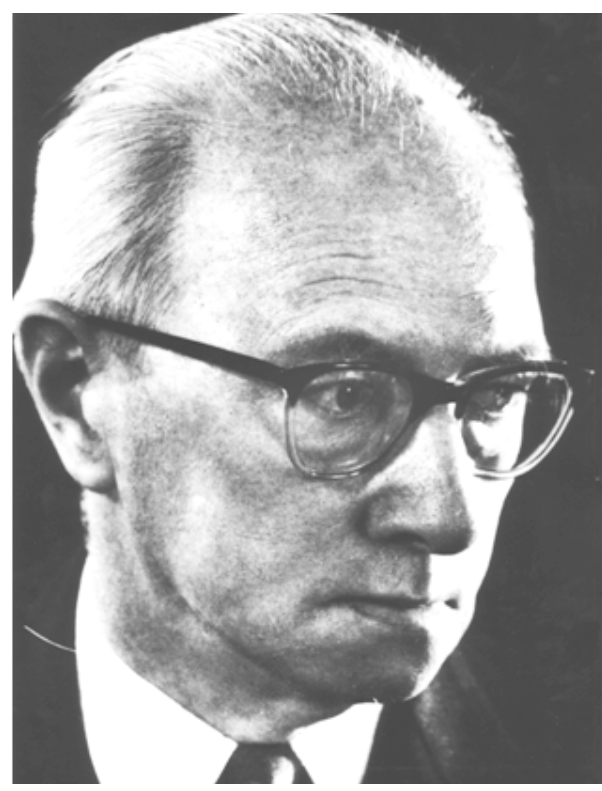

Fig. 11. Klaus Clusius (Director 1947-1963)

Clusius' achievements cover a broad field. In low-temperature physics he measured the heat capacities of $\mathrm{H}_{2}$, as well as $\mathrm{HD}$ and $\mathrm{D}_{2}$ but most impressively that of para- $\mathrm{H}_{2}$ with K. Hiller in 1929 , which included the temperature dependence of the heat of rotation. Later he discovered the $\lambda$-point of liquid helium with W. H. Keesom in 1930 (Fig. 12) and definitively determined the nuclear spin of deuterium as being 1 .

The Rockefeller fellowship brought Klaus Clusius to the laboratory of Hinshelwood in Oxford where he became involved with gas-phase reaction kinetics and catalysis.

Later in Zürich he extended his research to explosions and combustion processes and - after mastering isotope separation to exchange reactions and chemical reaction mechanisms.

In this context it is worth noting that Clusius' PhD student Ernst Schumacher

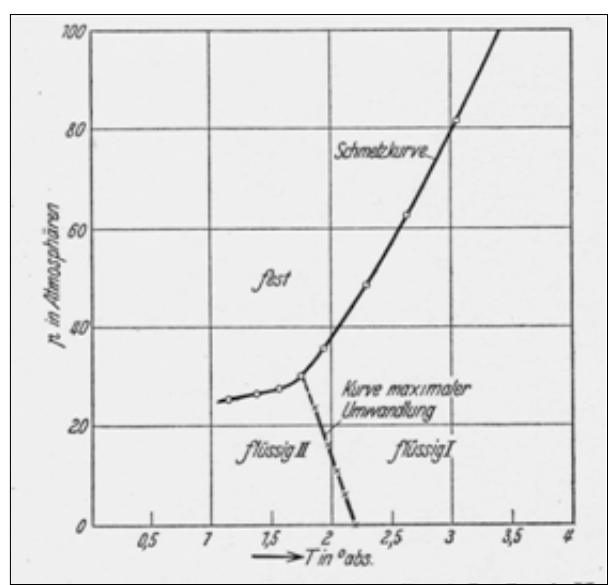

Fig. 12. 1930: First measurement of the $\lambda$-transition of helium ( $\mathrm{He}^{\mathrm{I}}$ (fluid)- $\mathrm{He}^{\mathrm{II}}$ (superfluid)) constructed in 1950/51 the first Swiss mass spectrometer, shown in an original photograph in Fig. 13. The world's first commercial instrument, an English product (Vickers), had become available in 1948.

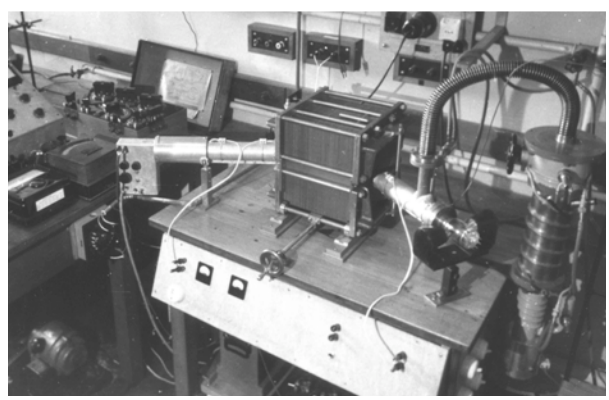

Fig. 13. The Clusius Lab with the first Swiss MS constructed by Ernst Schumacher in 1951

Mass spectrometry soon became an important tool in the laboratories of Clusius. Schumacher was later promoted to Director of the Institute of Inorganic Chemistry at the University of Zurich.

Probably the highest recognition Clusius received was for his isotope separation method. Based on the thermo-diffusion principle he was able to separate and accumulate isotopes in an unprecedented way. The Table in Fig. 14 shows the natural abundance and the achieved purity after application of his separation technique. The extremely high purity of isotopic species obtained by this technique was exploited for geological age determination, meter standard, isotopically labeled compounds in medicine, and so on.

The picture to the right in Fig. 14 is a mass spectrum of the six isotopes of $\mathrm{Kr}$. Positions 3 and 5 mark the pure 86 and 84 isotopes. Together with Schumacher, Clusius set a benchmark in 1959 by the $\operatorname{Ar}(38)$ isotope separation (last line). The purity reached $99.98 \%$ with a separation factor of 10 million. This isotope separation became an excellent source of income for the institute. The 'Clusius-Konto' still exists today and is used for special purposes such as the 75-year celebration. (Later Schumacher extended the technique and set a world record by achieving a purity of $99.9999 \%$ ).

An impression of the experimental techniques at the time is given in Fig. 15. It shows the 'private laboratory of Clusius' - as it was called - with the isotope separation apparatus consisting of about 50 separation tubes or 'Trennrohre'

An impressive piece of machinery was the 'Wasserstoffverflüssiger' or the 'bomb in the cellar' (Fig. 16). With his students, Clusius constructed a greatly respected hydrogen liquefier for his low-temperature work located in the basement of the chemistry building at Rämistrasse. As we know, the building is still there today which dem- 


\begin{tabular}{|c|c|c|c|c|c|c|}
\hline \multicolumn{5}{|c|}{ extract isotopes } & \multirow[b]{2}{*}{ normales kr } & \\
\hline Jahr & Isotop & $\begin{array}{l}\text { Natîrliche } \\
\text { Hâufigkeit }\end{array}$ & $\begin{array}{l}\text { Erreichte } \\
\text { Reinheit }\end{array}$ & $\begin{array}{l}\text { Totaler } \\
\text { Trennfaktor }\end{array}$ & & \\
\hline $\begin{array}{l}1939 \\
1939\end{array}$ & $\begin{array}{l}\mathrm{s}^{\mathrm{s}} \mathrm{Cl} \\
{ }^{\mathrm{r}} \mathrm{Cl}\end{array}$ & $\begin{array}{l}75,7 \\
24,3\end{array}$ & $\begin{array}{l}99,4 \\
99,6\end{array}$ & $\begin{array}{r}53 \\
775\end{array}$ & \multirow{9}{*}{ Trenarotir $k s$} & 2 \\
\hline 1940 & ${ }^{20 N e}$ & 90,51 & 99,8 & 52 & & \\
\hline $\begin{array}{l}1940 \\
1942\end{array}$ & 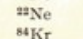 & $\begin{array}{r}9,21 \\
57.31\end{array}$ & $\begin{array}{l}99,7 \\
{ }_{98.3}\end{array}$ & $\begin{array}{r}330 \\
45\end{array}$ & & 3 \\
\hline 1942 & $\begin{array}{l}{ }^{*} \mathrm{Kr} \\
{ }^{6} \mathrm{Kr}\end{array}$ & 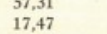 & $\begin{array}{l}98,3 \\
99,5\end{array}$ & 940 & & \\
\hline 1944 & 180 & 0,20 & 99,5 & 99000 & & \\
\hline 1950 & ${ }^{i_{N}}$ & 0,37 & 99,8 & 135000 & & \\
\hline 1952 & $\begin{array}{l}*_{\mathrm{A}} \\
\mathrm{w}_{1}\end{array}$ & 0.336 & 99,4 & $\begin{array}{l}50000 \\
45000\end{array}$ & & \\
\hline $\begin{array}{l}1953 \\
1955\end{array}$ & & $\begin{array}{l}1,1 \\
8,9\end{array}$ & $\begin{array}{l}99,8,8 \\
99,0\end{array}$ & 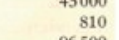 & & 2. \\
\hline 1956 & ${ }^{n_{\mathrm{Ne}}}$ & 0,275 & 99,6 & $\begin{array}{r}96500 \\
9750000\end{array}$ & \multirow{3}{*}{\multicolumn{2}{|c|}{ 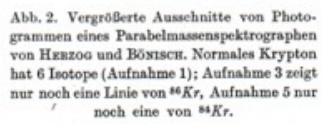 }} \\
\hline & & & & & & \\
\hline & 0,18 & Reacti & echa & & & \\
\hline
\end{tabular}

Fig. 14. Isotope separation by thermodiffusion

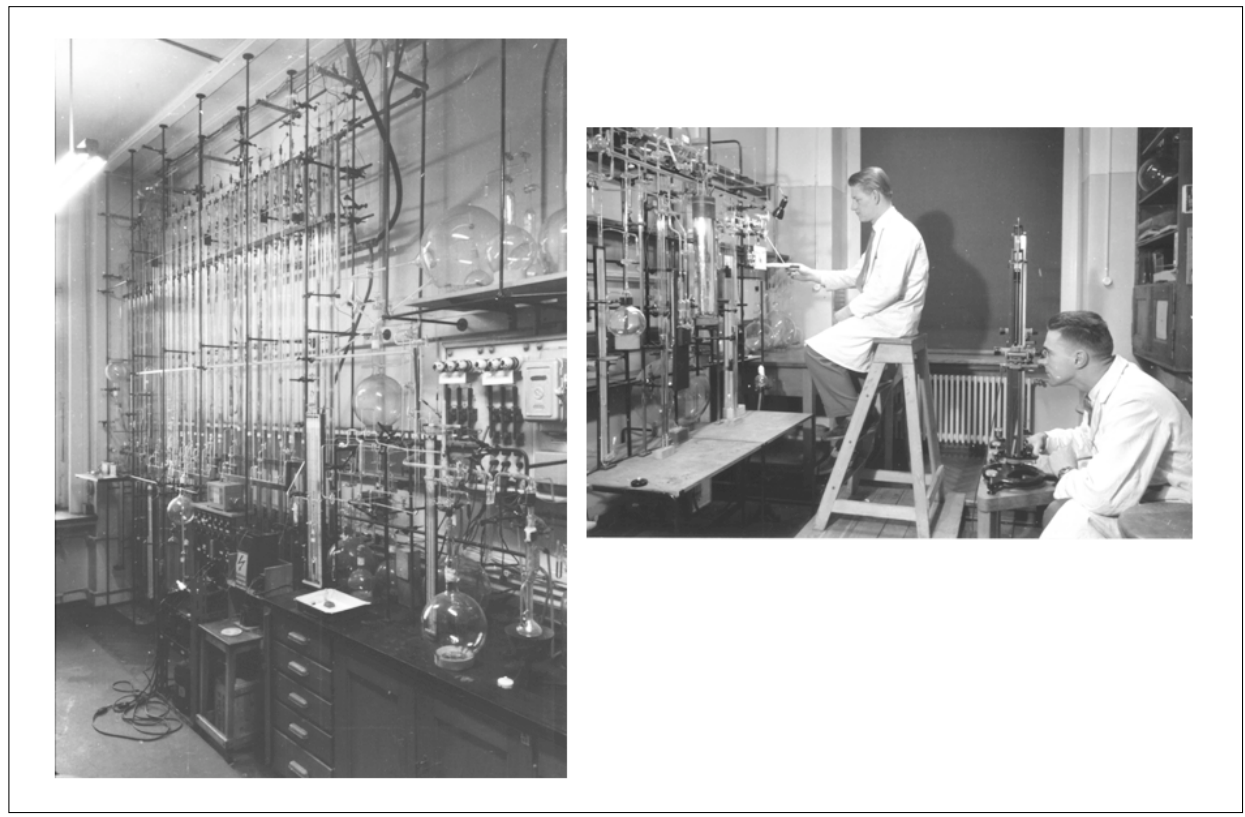

Fig. 15. Clusius' 'Privat Labor' with the isotope separation apparatus

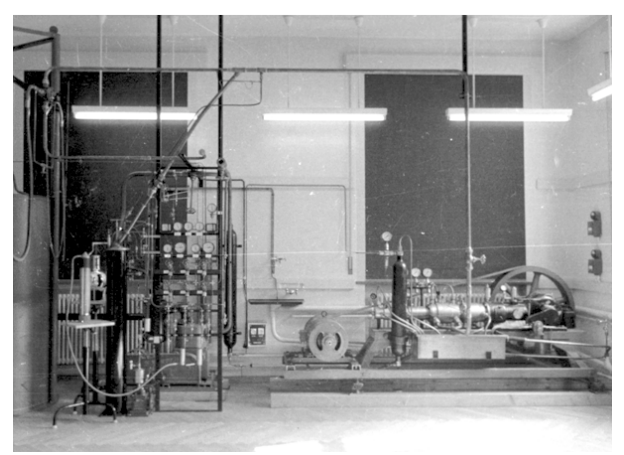

Fig. 16. Apparatus in the basement of Rämistrasse. $\mathrm{H}_{2}(\mathrm{l})$ production of $7 \mathrm{l} / \mathrm{h}$ at 160 Atü

onstrates the high safety standard of the apparatus designed by Clusius.

In 1963 two months after his 60th birthday Klaus Clusius died of a heart attack. Kuno Schleich his closest collaborator wrote, using the words of Lichtenberg: „Mir tut es allemal weh, wenn ein Mann von Talent
Heinrich Labhart combined molecular spectroscopy with the kinetics of interme-

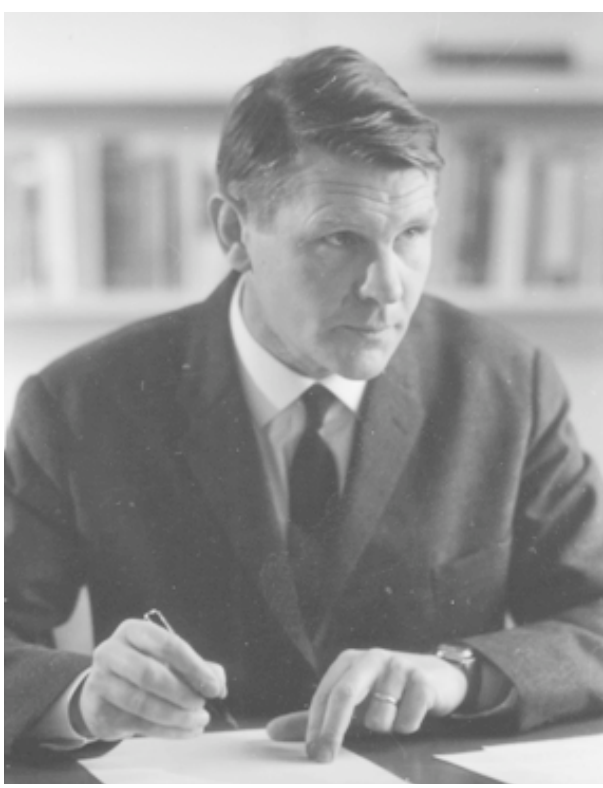

Fig. 17. Heinrich Labhart (Director 1964-1977)

diate or transient species. Thus his research was close in spirit to that of Victor Henri. His research projects included:

- Optical behavior of molecules in electric fields - dichroism and dipole moments

- Triplet-triplet absorption spectroscopy

- Triplet-triplet annihilation - influence of a magnetic field

- Primary photochemical processes

- Optical activity detected by emission

Labhart's great talent to construct simple, inexpensive but highly sophisticated apparatus was astonishing. He became particularly well-known for his studies of molecular properties in electric fields but also for his contributions to photochemical processes.

Between 1960 and 1970 the University enjoyed a period of rapid expansion. Labhart took this opportunity to convince the Erziehungsdirektion to establish two new faculty positions at our Institute. Hence, only one year after his start in Zürich, Labhart enjoyed the company of Georges Wagnière and four years later that of Hanns Fischer (Fig. 18). These two colleagues brought new directions to research and thus expanded the spectrum of physical chemistry at our institute.

The research of Wagnière was concerned with semi-empirical calculations of the molecular structure and spectroscopic properties of molecules. Chirality, optical activity and nonlinear optical effects in molecules were his favorite fields. Georges Wagnière completed his $\mathrm{PhD}$ in chemical physics at Harvard University in 1962 . He then undertook research at CIBA in Basel before taking up, initially, an assistant professorship at the University of Zurich in 1965 before being promoted ultimately to a 


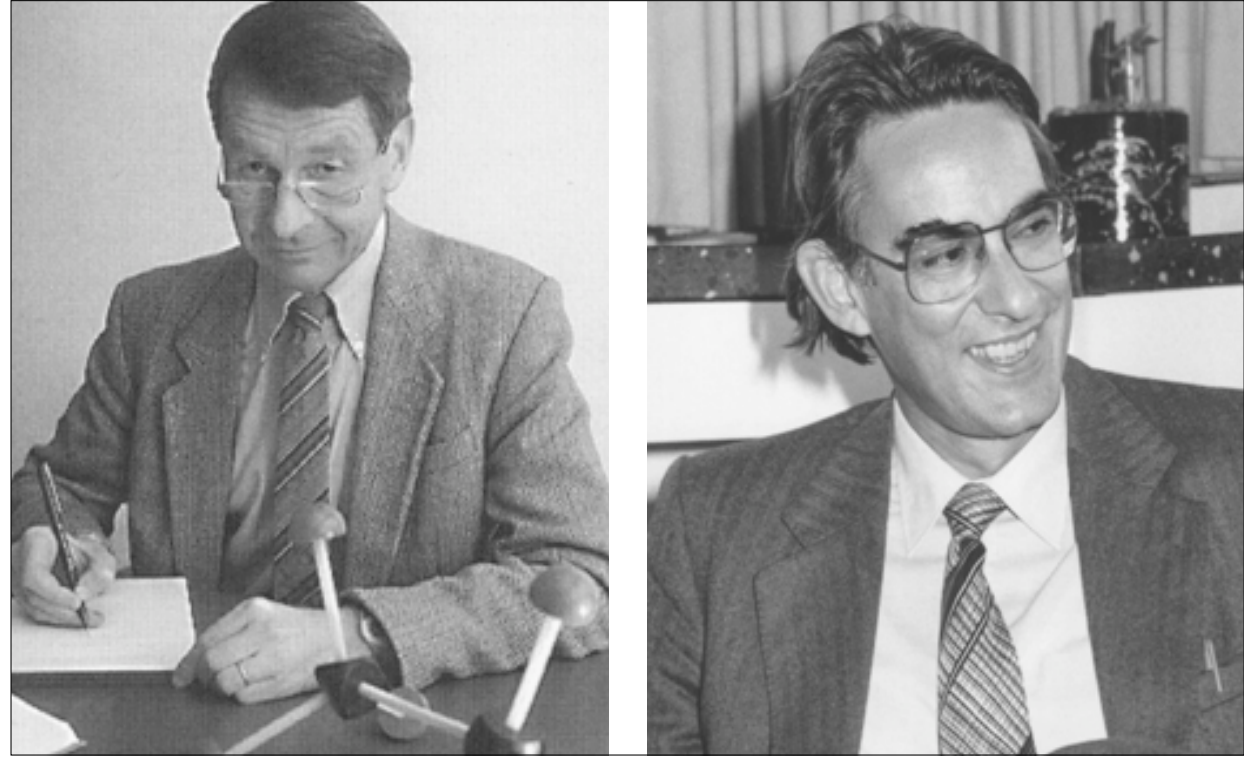

Fig. 18. New appointments: Georges H. Wagnière appointed in 1965, Hanns Fischer in 1969

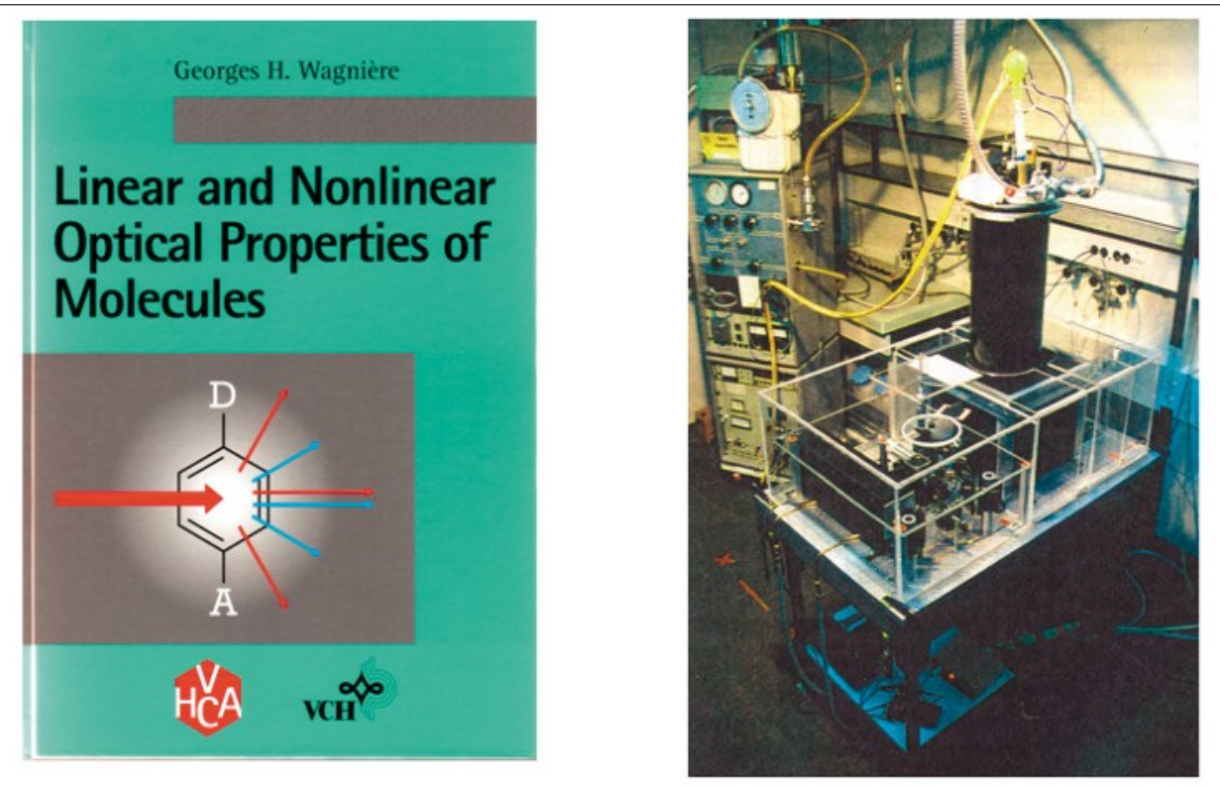

Fig. 19. Apparatus for the detection of the chirality effect in a magnetic field

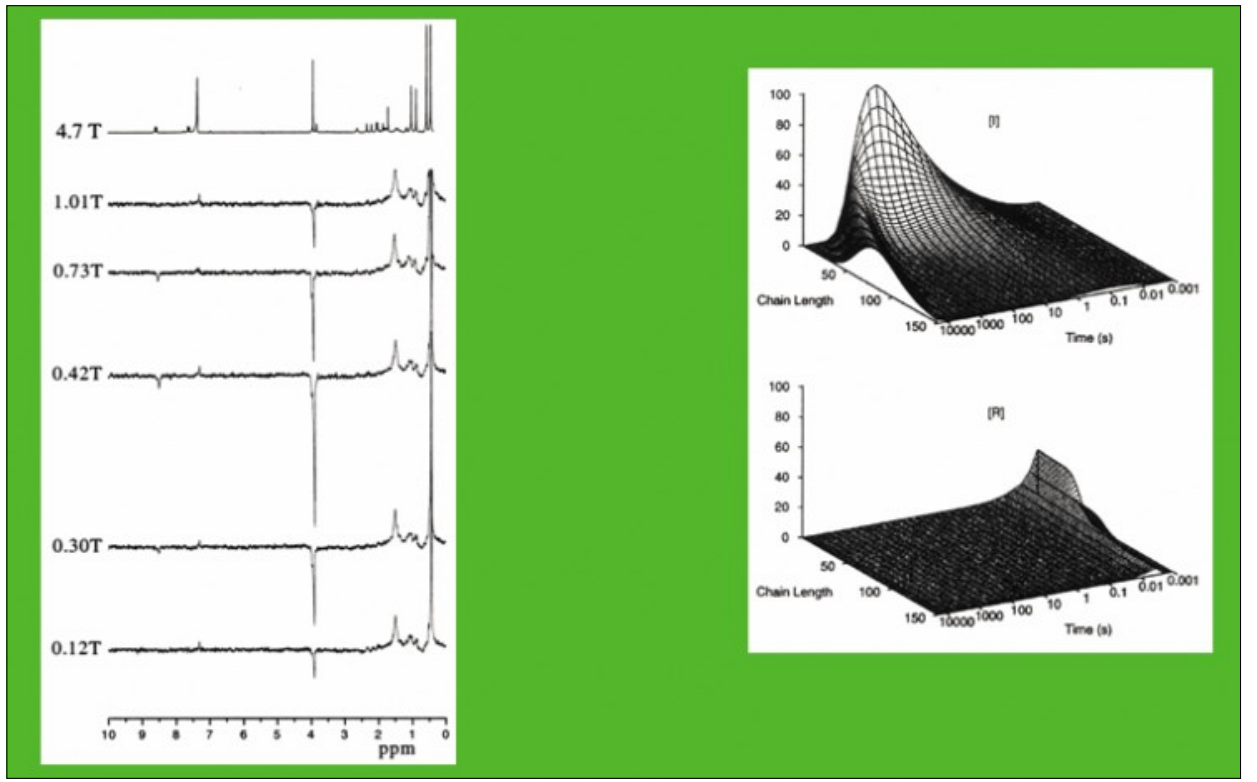

Fig. 20. CIDNP signals of transient free radicals full Professor. He became Professor emeritus in 1999.

His research interests included:

- Quantum chemical models of molecules

- Molecular chirality

- Optical activity - circular dichroism and magnetochiral effects

- Nonlinear optical properties of molecules

But Wagnière was not only a theoretician. Later in his career he became also involved in experimental work with the goal to prove his theoretical predictions with experiments, particularly in the fields of optical activity and nonlinear optical phenomena. Fig. 19 shows on the right side his setup for the detection of the chirality effect in a magnetic field.

Hanns Fischer wrote his dissertation at the University of Darmstadt in 1963, followed by his habilitation in 1966 at the same university. He was also division manager of the Deutsches Kunststoffinstitut in Darmstadt. In 1969 he became an associate and then later full professor at the University of Zurich. Only four years after his retirement Hanns Fischer died unexpectedly in February 2005. In him we lost a fine colleague, a highly appreciated teacher, and an outstanding scientist.

Fischer's main research interest were free radicals: their production, their kinetics and their reactions under different solvent conditions detected and monitored by magnetic resonance and/or optical spectroscopy. His discovery of the phenomenon of chemically induced dynamic nuclear polarization together with Joachim Bargon deserves a special mention. They established this new method (CIDNP) in 1967.

The CIDNP signals shown on the left side of Fig. 20 have been detected by NMR spectroscopy. The spectra are based on a nuclear spin state distribution produced from radical pairs generated in photochemical reactions. Hanns Fischer exploited this method to characterize transient free radicals and their reaction mechanism in solution. Beside these mechanistic studies, his research became more and more devoted to the kinetics of radicals such as 'persistent' and 'living' radicals involved in polymerization processes.

1971 was a very special year for the University of Zürich; the people of the Canton of Zürich voted overwhelmingly for a new University site on the Irchel. For the natural and the medical sciences this expansion was of utmost importance. In 1978 the first phase of the Irchel complex was completed and the Departments of Chemistry and Biology were among the first to move to the new campus equipped with splendid laboratories and lecture halls (Fig. 21). 


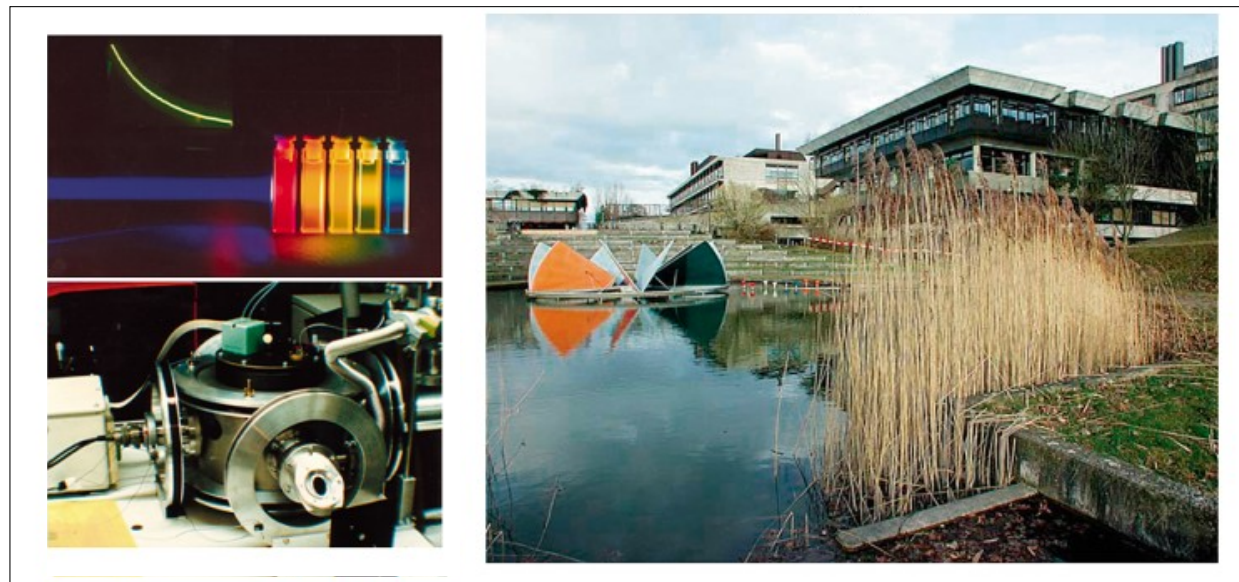

Fig. 21. 1978: The Institute moves to the new campus on the Irchel

Heinrich Labhart, who - together with Hanns Fischer and Georges Wagnière - had planned the new Physical Chemistry Institute on the Irchel, died unexpectedly of a heart attack in 1977 at an age of only 58. Both the Institute and Faculty were deeply moved by the death of this greatly esteemed scientist and teacher.

\section{8-2001}

In 1979 J. Robert Huber succeeded Heinrich Labhart (Fig. 22), moving from Konstanz to the new campus which radiated optimism. Huber completed his dissertation in physical chemistry under the supervision of H. Günthard at the ETH in 1966. After a period in the US undertaking research at the US Army Pioneering Research Labs Natick in Massachusetts and as associate professor at Northeastern University, Boston he became Professor at the University of Konstanz in 1973. He became Professor emeritus in 2001.

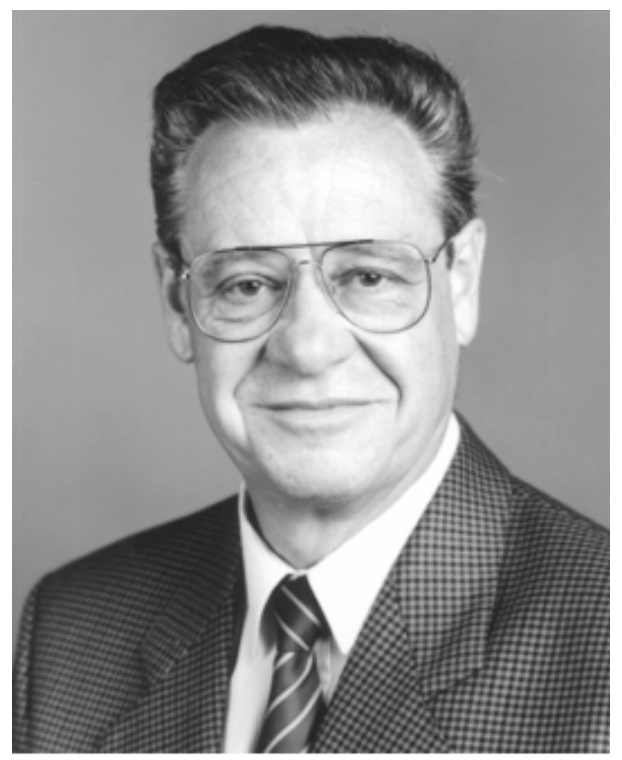

Fig. 22. J. Robert Huber
At the time of his move to Zürich, tunable lasers and cold molecular beams were pushing spectroscopy and chemical dynamics forward. Accordingly, Huber's research included:

- Laser spectroscopy - frequency and time domain, matrix isolation spectroscopy

- Molecular dynamics - photodissociation, elementary chemical reactions, atmospheric chemistry

- Surface science - laser ablation, thin film production and growth mechanisms

In photochemistry, his group was mainly concerned with processes in atmospheric chemistry (Fig. 23). Over two dozen molecules or radicals of atmospheric relevance were studied with respect to their direct or indirect photochemical decay processes. For selected species, quantum chemical and dynamics calculations revealed their microscopic decay pathway and the energy distribution on the product species.

The first spectra of time-dependent molecular spectroscopy after compensation of the earth's magnetic field were obtained in 1981. The quantum beat spectra in Fig. 24 show the hyperfine structure of a transient singlet state and its corresponding triplet state with the highest (or natural line-width) resolution. The snapshot catches the two successful students in the 'Eureka' pose.

In the field of surface science a new technique for controlling the production of thin films was introduced: pulsed reactive crossed-beam laser ablation (Fig. 25).

This method combines pulsed laser ablation with a synchronized pulsed gas source for the non-thermal synthesis and growth of novel advanced materials in thin film form as micro- and nanostructures. The example shows film structures of transition-metal carbonitride, with various ratios of carbon to nitrogen.

In 1981 Karl Lendi and Henning Paul joined the Institute as 'Privatdozenten' and later as 'Titularprofessoren' (Fig. 26). Both recently retired. Karl Lendi's research interest was mainly concerned with irreversible quantum dynamics in open systems including interaction with an environment. In this context, rigorous mathematical methods and their applications were developed for relaxation and dissipation processes. Henning Paul focused on Spin Chemistry, the question how chemical reactions are influenced by magnetic fields using time-resolved ESR methods. Marco Nonella joined our Institute in 1992 as 'Bundesprofessor' of Computational Science. He left us in 1996, first moving to our Biochemistry Institute and later became a faculty member at the University in Munich. His research is centered on applications of quantum chemical methods to complex biological systems and surfaces.

During the 75 years of the Institute 15 'Privatdozenten', $180 \mathrm{PhD}$ students and almost the same number of postdoctoral stu-

\section{Atmospheric Chemistry}

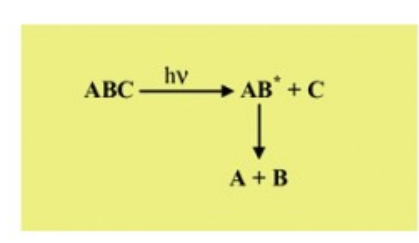

\section{STRATOSPHERE}

$\mathrm{CF}_{2} \mathrm{Cl}_{2}, \mathrm{CFCl}_{3}, \mathrm{CF}_{2} \mathrm{Br}_{2}$,

$\mathrm{CF}_{2} \mathrm{BrCl}, \mathrm{CHFCl}_{2}, \mathrm{CHCl}_{3}$

$\mathrm{CF}_{2}{ }^{\circ}, \mathrm{CCl}_{2}{ }^{\circ}, \mathrm{OCl}_{2}{ }^{\circ}, \mathrm{ClO}_{2}{ }^{\circ}, \mathrm{ClO}_{2}\left(\mathrm{H}_{2} \mathrm{O}\right)_{\mathrm{m}}$

$\mathrm{SO}_{2}, \mathrm{~N}_{2} \mathrm{O}, \mathrm{R}-\mathrm{OCl}, \mathrm{SO}_{3}, \mathrm{O}_{3}$

$\mathrm{HNO}_{3}\left(\mathrm{H}_{2} \mathrm{O}\right)_{\mathrm{m}}, \mathrm{ClNO}_{2}\left(\mathrm{H}_{2} \mathrm{O}\right)_{\mathrm{m}}$

\section{TROPOSPHERE}

$\mathrm{NO}_{2}, \mathrm{HNO}_{3}, \mathrm{HONO}, \mathrm{CINO}_{2}$

$\mathrm{CH}_{3} \mathrm{ONO}_{2}, \mathrm{CH}_{3} \mathrm{ONO},\left(\mathrm{CH}_{3} \mathrm{ONO}\right)_{\mathrm{m}}$

$\mathrm{R}-\mathrm{O}-\mathrm{O}-\mathrm{H}, \mathrm{R}_{2}-\mathrm{C}=\mathrm{O}, \mathrm{R}-\mathrm{CH}=\mathrm{O}$

RO*
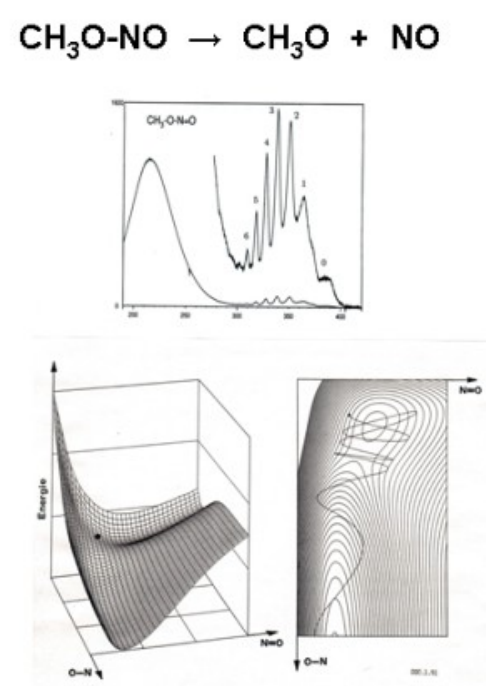

Fig. 23. Processes in atmospheric chemistry 


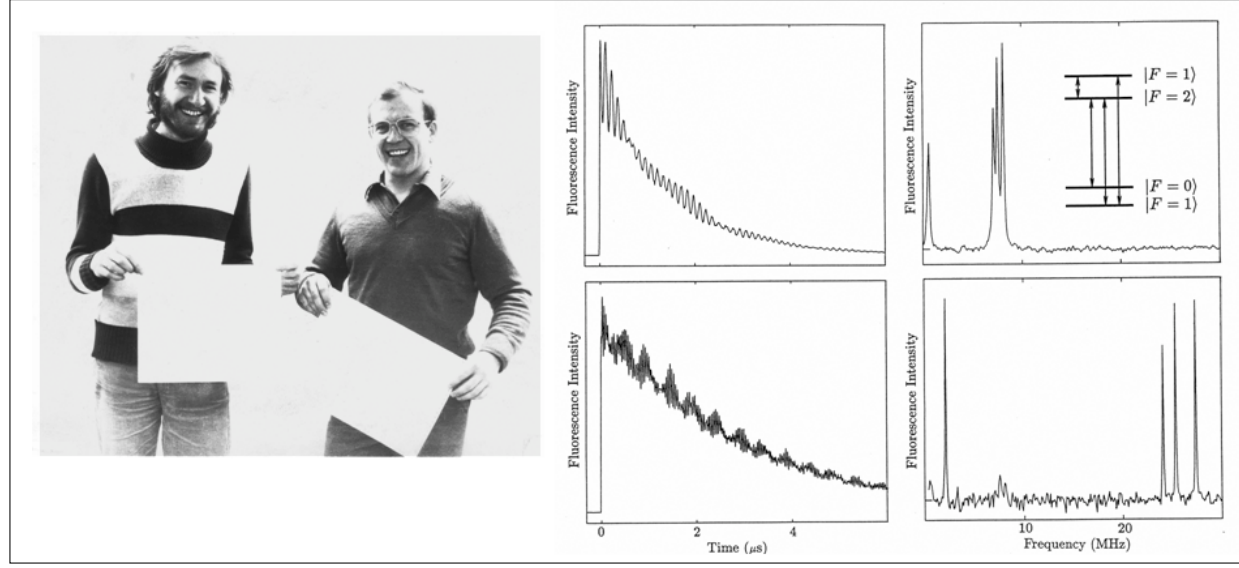

Fig. 24. 1981: the first spectra of time-dependent molecular spectroscopy after compensation of the Earth's magnetic field (quantum beat spectroscopy)
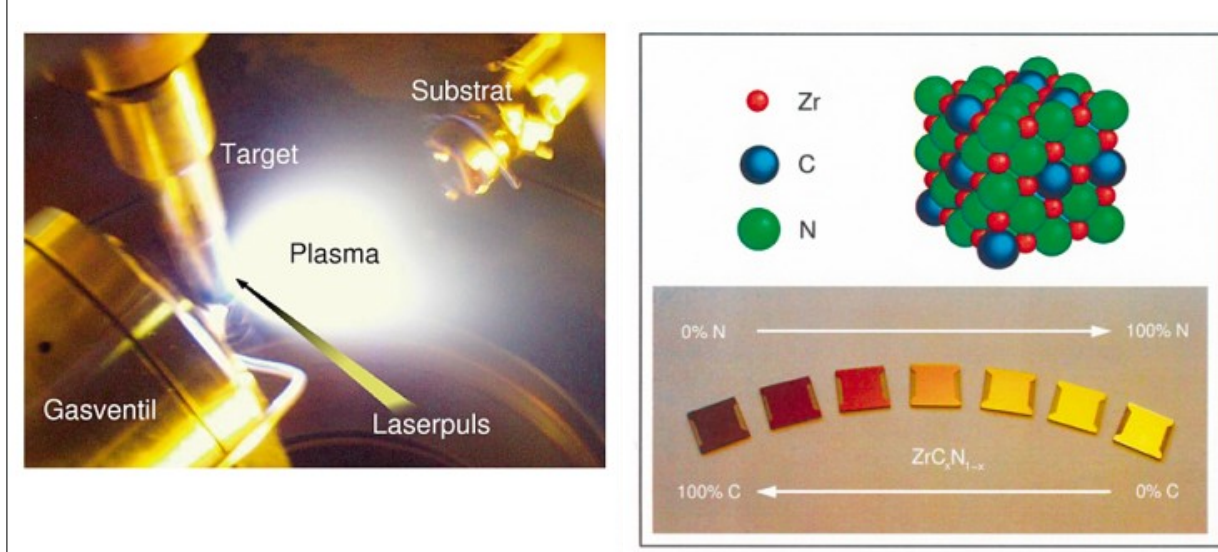

Fig. 25. Pulsed reactive crossed-beam laser ablation and thin film production
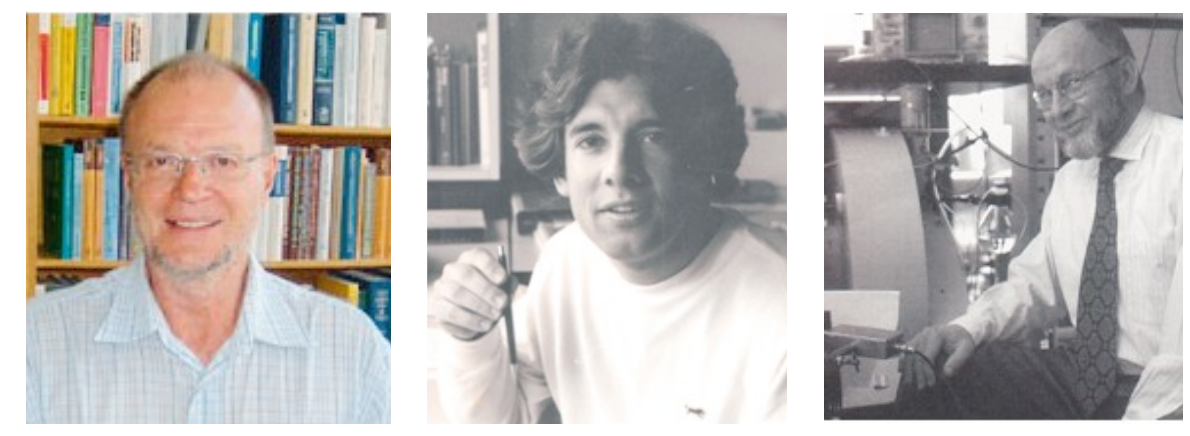

Fig. 26. Profs Karl Lendi, Marco Nonella and Henning Paul
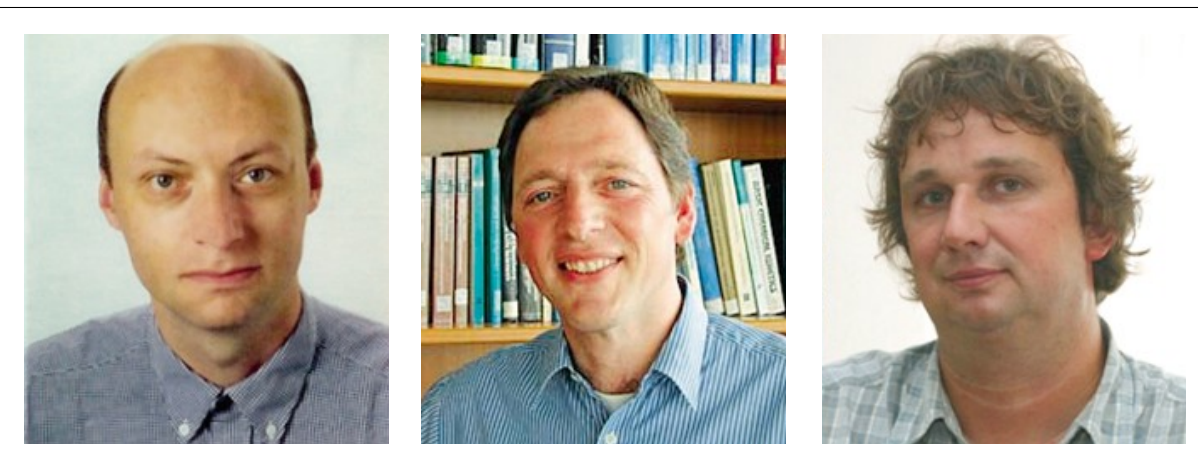

dents contributed with their thesis works and their publications to the scientific accomplishments of Physical Chemistry at our University. Their dedication and passion to science were also a prerequisite for a successful Institute; they truly deserve our gratitude.

\section{The New Generation}

This was the story of the past. The present and the future of the Institute belong to the professors Stefan Seeger, Peter Hamm and Jürg Hutter, their students and collaborators (Fig. 27).

Stefan Seeger, who is presently acting as Director of the Institute, pursues a research program in the field of biophysical chemistry. His group studies ultra-sensitive analytical methods applying time-resolved fluorescence spectroscopy in order to characterize complex molecules and their dynamical behavior in solution and on surfaces. Further research topics deal with the structure and interaction of biomolecules on surfaces and the development of biophysical methods applicable in neuroscience.

Peter Hamm and his students are involved in femtosecond infrared spectroscopy. They study the structural dynamics of complex molecules in the condensed phase using, among various techniques, two-dimensional IR spectroscopy. They analyze the nuclear motions of molecular systems and identify those degrees of freedom which are relevant for conformational changes. Their novel methods allow them to address problems such as protein folding, energy transport in molecules, elementary structural processes in liquids as well as mechanistic features of IR-driven photochemistry.

Jürg Hutter represents the field of theoretical physical chemistry at the Institute. With his group he works on the development and application of new methods in computational chemistry. In particular, he and his students are using the density functional theory (DFT) to study large systems in the condensed phase. Time-dependent DFT, property evaluation - such as magnetic properties - for large systems and linear scaling methods are among the topics of their current research.

With the present ends this brief account of the history of Physical Chemistry at the University of Zürich. May this fine institution of education and research also prosper in the future.

Received: December 1, 2007

Fig. 27. Profs Jürg Hutter, Stefan Seeger and Peter Hamm 